\title{
HYPOXIC VENTILATORY RESPONSES DURING THIOPENTONE SEDATION AND ANAESTHESIA IN MAN
}

\author{
R.L. KNILL, S. BRIGHT, AND P. MANNINEN
}

\begin{abstract}
ANAESTHETIZED MAN is vulnerable to episodes of hypoxia, both during anaesthesia and in the recovery phase. Thus the activity of the usual compensatory responses to hypoxia during anaesthesia is of clinical interest. There has been considerable investigation of the ventilatory and cardiovascular responses to experimental hypoxia in conscious man and in conscious and anaesthetized animals. ${ }^{1.2}$ However, until recently, there was virtually no information on these important chemoreflexes in anaesthetized man. It is believed that there is considerable species-specificity in the magnitude of hypoxic responses of animals and man, both awake and anaesthetized; ${ }^{3-6}$ therefore, information derived from anaesthetized animals cannot be confidently applied to anaesthetized man.
\end{abstract}

We have recently observed that light halothane anaesthesia totally abolishes the ventilatory response to hypoxia in man, at dosages where resting ventilation and the ventilatory response to carbon dioxide remain present and relatively brisk. ${ }^{6}$ In addition, halothane or nitrous oxide in sub-anaesthetic dosages markedly depresses the ventilatory response to hypoxia, with no detectable effect on either resting ventilation or the carbon dioxide response. ${ }^{6.7}$ Do these newlyrecognized effects of halothane and nitrous oxide on the hypoxic chemoreflex represent a general characteristic of anaesthetics in man?

This work examines ventilation and the ventilatory responses to hypoxia and hypercarbia in human subjects while awake and during sedation or anaesthesia with thiopentone. During thiopentone induced sedation, values of ventilation and responses to hypercarbia and hypoxia were similar to the awake control. Thiopentone

R.L. Knill, M.D., F.R.C.P.(C), Assistant Professor, Department of Anaesthesia, University Hospital, University of Western Ontario, London, Canada.

S. Bright, M.D. and P. Manninen, M.D. Residents, Department of Anaesthesia, University Hospital, University of Western Ontario, London, Canada.

This work was supported by the Medical Research Council of Canada, Development Grant 150.

Address reprint requests to Dr. R.L. Knill, Department of Anaesthesia, P.O. Box 5339, Postal Stn. A, London, Ontario. N6A SA5. anaesthesia decreased both ventilation and the carbon dioxide response to approximately 40 per cent of awake controls. Similarly, anaesthesia attenuated the ventilatory response to hypoxia to a mean of 44 per cent of the isocapnic control. The mean absolute hypoxic responsiveness of our slightly hypercapnic anaesthetized subjects was similar to that of normocapnic awake controls.

\section{METHOD}

The subjects of this study were young (18 to 30 years of age), completely fit, on no medications and fully agreeable to the investigation after being fully informed of the nature, purposes and risks involved. Altogether there were twenty subjects, of whom twelve were males and eight females. Their mean age ( \pm S.D.) was $23 \pm 4$ years, weight $68 \pm 9 \mathrm{~kg}$ and height $174 \pm 6 \mathrm{~cm}$.

The five subjects for the sedation portion of the study were physicians or respiratory technologists, all of whom were familiar with investigations of ventilatory control. Each was studied twice, while sedated and fully awake. The ten subjects investigated during thiopentone anaesthesia were patients who were to undergo elective dental surgical procedures. None had previously served as an experimental subject. Five of the anaesthetized patient subjects were restudied in the control awake state; five were not available for awake study; their controls were five additional non-medical volunteers. (Statistically, the se controls were treated as unpaired.)

Subjects of the sedation group were studied in our laboratory at a time of convenience. They were permitted to eat on the day of testing, but were requested to avoid caffeine-containing drinks. Each was positioned supine with a blood pressure cuff, electrocardiograph (EKG) monitor and intravenous catheter in place. Sedation was induced with sodium thiopentone $2-3 \mathrm{mg} / \mathrm{kg}$ administered intravenously over four or five minutes and maintained with an infusion of thiopentone 0.1 per cent at a rate of 0.1 to $0.3 \mathrm{mg} / \mathrm{kg} / \mathrm{min}$. To measure ventilation, a nose-clip was applied and the subject held a mouthpiece. Tests were 
performed with each subject slightly drowsy but still conscious and after ventilation and end-tidal $\mathrm{PCO}_{2}$ had been steady for five minutes.

Studies of anaesthetized volunteers took place in an operating room laboratory during the one hour before their planned surgical procedure. Subjects had fasted overnight and were not premedicated. Positioned supine, with an intrave nous established and blood pressure and electrocardiograph monitors in place, each received sodium thiopentone 4 to $6 \mathrm{mg} / \mathrm{kg}$ intravenously, to the point of abolishing the eyelash and eyelid reflexes. Following succinylcholine $1 \mathrm{mg} / \mathrm{kg}$ and topical lidocaine anaesthesia of the glottis and upper trachea, the trachea was intubated with an 8 or $9 \mathrm{~mm}$ cuffed tracheal tube. With spontaneous ventilation re-established and while inhaling 100 per cent oxygen, subjects received an intravenous infusion of thiopentone 0.1 per cent at a rate of 0.2 to $0.4 \mathrm{mg} / \mathrm{kg} / \mathrm{min}$, adjusted so that there was a light level of anaesthesia with the eyelid reflex suppressed and both regular ventilation and a constant end-tidal $\mathrm{PCO}_{2}$. Achievement of these end-points usually required 10 to $15 \mathrm{~min}$ utes of infusion.

In both sedated and anaesthetized states, a one-minute period of unstimulated ventilation was measured while the subject continued to inhale oxygen from a non-rebreathing circuit. Endtidal carbon dioxide tension was noted. Subsequently, the ventilatory response to isocapnic hypoxia was evaluated by the non-rebreathing technique of Weil, et al ${ }^{8}$ Oxygen in the inspired gas was gradually replaced with air and then a mixture of air and nitrogen, such that the endtidal oxygen tension decreased to approximately $5.32 \mathrm{kPa}(40$ torr) over an 8 to 10 minute period. The lowest level of oxygen tension was maintained for 20 to 30 seconds. Throughout the hypoxic test, end-tidal carbon dioxide tensions were held constant by adding carbon dioxide to inspired gas as required. After completing the test, the subject breathed oxygen again for at least five minutes. With ventilation and end-tidal $\mathrm{PCO}_{2}$ again steady, progressive hypercarbia was induced by the method of Read. 9 The airway was connected to a closed rebreathing circuit (approximate internal volume 10 litres), containing 7 per cent carbon dioxide in oxygen. After four or five large tidal volume exchanges with the circuit, the subject breathed spontaneously while his carbon dioxide level progressively increased. The test proceeded to a circuit carbon dioxide concentration of 9 to 9.5 per cent which was usually achieved within five or six minutes. A 5 to 10 minute period of unstressed oxygen breathing followed. Finally, four subjects of the anaesthetized group received doxapram $0.4 \mathrm{mg} / \mathrm{kg}$ intravenously as a bolus, while oxygen breathing continued. Ventilation was monitored over the 60 seconds following injection. During all tests, ventilation and end-tidal gas tensions were continuously measured and recorded.

Throughout the study periods, thiopentone infusions continued to maintain as nearly constant a state of resting ventilation and end-tidal $\mathrm{PCO}_{2}$ as was possible. The volume of intravenous fuid ( 5 per cent dextrose in 0.2 per cent saline) infused ranged from 250 to $1000 \mathrm{ml}$.

Subjects of the sedation group were studied in the control or awake state one to three hours before receiving their sedation. Testing of the anaesthetic group volunteers in the awake state was conducted one to three weeks following their anaesthetic and surgical procedure. Each awake subject sat in a comfortable chair in a moderately darkened laboratory and breathed through a mouthpiece with a nose-clip in place. Ventilation and responses to hypoxia, hypercarbia and doxapram were determined by the methods employed in the sedated and anaesthetized states. In subjects of the anaesthetized group, measurements of both ventilation and the response to hypoxia were made at the end-tidal carbon dioxide tension which had been present during anaesthesia. In the five control subjects who had not been anaesthetized, carbon dioxide levels were matched to the mean anaesthetic value of $5.72 \mathrm{kPa}$ (43 torr). This somewhat elevated carbon dioxide level was recreated in the awake state by inhaling an appropriate amount of carbon dioxide for a 10 to 12 minute equilibration period.

In all tests, airway gas was continuously sampled and analyzed for its carbon dioxide and oxygen tensions by a Perkin-Elmer " 1100 " mass spectrometer. Dried gas concentration readings were regularly calibrated with Canadian Liquid Air Specialty Gases and converted to gas tensions with daily measurements of barometric pressure. During tests, carbon dioxide and oxygen signal outputs from the mass spectrometer were recorded on a time-based strip polygraph, from which end-tidal plateau tensions were read. In hypoxic tests, values of end-tidal oxygen tension were assumed to represent the arterial oxygen stimulus, an assumption which introduces a small and unimportant error in young conscious and anaesthetized subjects during hypoxic testing. ${ }^{6}$ In hypercarbic studies using the method of 
Read, values of increasing end-tidal carbon dioxide are believed to represent the increases in brain or medullary carbon dioxide; that is, the central carbon dioxide stimulus. ${ }^{10}$

Inspired minute ventilation was measured with a calibrated pneumotachograph placed in the inspiratory limb of each circuit and coupled with a differential pressure transducer. Ventilatory frequency was found from the recorded airflow signal and tidal volume from the recorded electronic integration of that signal. Instantaneous ventilation was computed from the averaged tidal volumes and frequencies of at least three consecutive breaths. All values of ventilation are expressed at BTPS.

Hypoxic responses are reported as the " $\Delta \dot{V}{ }_{45}$ "; that is the increment in ventilation between two points in the response - the $\mathrm{PET}_{\mathrm{O}_{2}}$ of $53.2 \mathrm{kPa}\left(400\right.$ torr) and the $\mathrm{PET}_{\mathrm{O}_{2}}$ of $5.99 \mathrm{kPa}$ (45 torr). We also report the " $A$ " parameter of the entire hypoxic response, " $A$ " representing the degree of rounding of the hyperbolic relationship between inspired ventilation and $\operatorname{PET}_{\mathrm{O}_{2}}$. " $\mathrm{A}$ "' is found by solving the regression equation

$$
\dot{\mathrm{V}}_{1}=\dot{\mathrm{V}}_{\mathrm{I}_{0}}+\frac{\mathrm{A}}{\mathrm{PO}_{2}-30},
$$

inserting experimental values of $\vec{V}_{1}$ found at various values of $\mathrm{Po}_{2}$. Values of both " $\Delta \dot{V}_{I_{4}}$ " and "A" relate directly to the magnitude of hypoxic response. Carbon dioxide responses are represented by the slope of the least squares linear regression of ventilation as a function of $\mathrm{PCO}_{2}$ and the actual ventilation at a $\mathrm{PCO}_{2}$ of $7.32 \mathrm{kPa}$ (55 torr). The reported response to doxapram is the maximum increment in instantaneous ventilation during the minute following injection.

Student t-tests were employed to evaluate possible differences in thiopentone and control results. Sedation and control data were considered paired; anaesthesia and control data unpaired. $P$ values of 0.05 or less were regarded as indicative of a significant difference.

\section{Results}

There were no serious untoward effects of these studies. Two sedated subjects experienced total amnesia for the study period and two who had been previously tested during halothane and enflurane sedation (0.1 MAC) remarked on the greater "hangover" effect of thiopentone sedation. Anaesthetized subjects who received total thiopentone dosages greater than one gram experienced prolonged post-anaesthetic drowsi- ness. Sedation produced no detectable changes in blood pressure or pulse; anaesthesia reduced systolic and diastolic blood pressures 10 to 30 per cent from awake levels, while increasing pulse rate slightly. During hypoxic and hypercarbic challenges, in all states, blood pressure and pulse rate increased variably and only moderately; individual value of systolic pressure never exceeded $19.95 \mathrm{kPa}$ (150 torr); pulse rate was never in excess of 115 beats $/ \mathrm{min}$. There were no arrhythmias observed.

Thiopentone sedation did not significantly alter resting ventilation, end-tidal carbon dioxide tension, and ventilatory responses to isocapnic hypoxia and hyperoxic hypercarbia (Table I). Thiopentone anaesthesia reduced isocapnic ventilation and the ventilatory responses to both hypoxia and hypercarbia (Table I, Figure 1). During thiopentone anaesthesia, the mean increment in ventilation ( \pm S.E.M.) after the bolus injection of doxapram $0.4 \mathrm{mg} / \mathrm{kg}$ was $5.0 \pm 0.7 \mathrm{l} / \mathrm{min}$, a value significantly less than the awake control of $16.1 \pm 0.71 / \mathrm{min}$.

To compare the effects of sedation and anaesthesia on ventilation and each response tested, we constructed a bar diagram depicting the mean magnitude of each variable measured during sedation or anaesthesia as a percentage of control or awake (Figure 2). Values employed for this comparison were: for ventilation, the inspired minute ventilation; for the carbon dioxide response, the slope of the ventilation: $\mathrm{PCO}_{2}$ relationship; for the hypoxic response, the $\Delta \dot{V}_{1_{4}}$; and for the doxapram response, the maximum increment in ventilation. During sedation, no variable changed significantly from control. During anaesthesia, there were approximately equivalent depressions of isocapnic ventilation and each of the three ventilatory reflexes tested.

\section{Discussion}

The hypoxic ventilatory reflex serves to defend arterial oxygenation, particularly when oxygenation is threatened by reduced $\mathrm{Fl}_{\mathrm{O}_{2}}$ or defects in intra-pulmonary gas exchange. It is initiated by receptors in the phylogenetically very old peripheral chemoreceptors, which in man are the carotid bodies." The entire reflex pathway has been traditionally viewed as rugged and hearty and, in contrast to the refiex response to carbon dioxide, not readily attenuated by ventilatory disease or drugs depressing the central nervous system. ${ }^{1.12}$ More recently, this hypothesis of peripheral chemoreflex resilience has been chal- 
TABLE I

VENTILATION AND RESPONSES TO HYPOXIA AND HYPERCARBIA

\begin{tabular}{|c|c|c|c|c|}
\hline & Awake & Sed'n. & Awake & Anaes. \\
\hline $\begin{array}{l}\text { Ventilation } \\
\text { (L/min.) }\end{array}$ & $\begin{array}{c}n=5 \\
6.6 \pm 0.8\end{array}$ & $\begin{array}{c}n=5 \\
7.6 \pm 1.1\end{array}$ & $\begin{array}{c}n=10 \\
15.9 \pm 2.0^{*}\end{array}$ & $\begin{array}{c}n=10 \\
6.9 \pm 0.9^{* * *}\end{array}$ \\
\hline $\begin{array}{l}\text { PET }_{\text {CO }} \\
\text { (torr) }\end{array}$ & $41 \pm 0.9$ & $41 \pm 1.2$ & $44 \pm 1.2^{* *}$ & $43 \pm 1.5$ \\
\hline $\begin{array}{l}\text { Hypoxic Response } \\
\Delta \dot{\mathrm{Y}} \mathrm{I}_{45} \\
\text { (L/min.) } \\
\text { "A" } \\
\text { (L·torr/min.) }\end{array}$ & $\begin{array}{l}7.0 \pm 1.8 \\
119 \pm 27\end{array}$ & $\begin{array}{l}6.4 \pm 1.0 \\
102 \pm 18\end{array}$ & $\begin{array}{c}15.9 \pm 3.4 \\
289 \pm 73\end{array}$ & $\begin{array}{l}7.0 \pm 1.6^{* * *} \\
131 \pm 28^{* * *}\end{array}$ \\
\hline 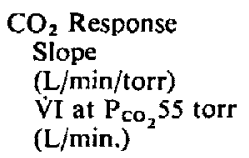 & $\begin{array}{r}1.7 \pm 0.2 \\
20.2 \pm 2.0\end{array}$ & $\begin{array}{r}1.3 \pm 0.1 \\
21.1 \pm 1.1\end{array}$ & $\begin{array}{r}2.0 \pm 0.3 \\
29.1 \pm 4.5\end{array}$ & $\begin{array}{r}0.7 \pm 0.2^{* * *} \\
12.3 \pm 1.6^{* * *}\end{array}$ \\
\hline
\end{tabular}

Values are mean \pm S.E.M.

*Value of ventilation at $\mathrm{PET}_{\mathrm{CO}_{2}}$ indicated.

** PET $\mathrm{CO}_{2}$ matched to anaesthetic value by inhaling $\mathrm{CO}_{2}$.

*** Significantly different from awake value $(\mathrm{p}<0.05)$.

lenged, Chronic obstructive pulmonary disease, obesity and narcotic administration all reduce hypoxic responsiveness, albeit only to the extent of reduced ventilation and/or ventilatory response to carbon dioxide. ${ }^{13-15}$ We have recently reported that light halothane anaesthesia totally eliminates the normal ventilatory response to hypoxia and, in some individuals, unmasks slight ventilatory depression during hypoxia. ${ }^{6}$ The impact of halothane on the hypoxic chemoreflex is far out of proportion to effects on ventilation and the carbon dioxide response and represents the most striking exception to the traditional view. The aim of the present work was to assess hypoxic responsiveness during thiopentone sedation and anaesthesia in man.

To compare ventilation and multiple ventilatory reflexes in the same subject, a reasonably steady state of ventilation is required. While this can be achieved with relative ease in the conscious state and during inhalational anaesthesia or sedation, "states" induced by intravenous thiopentone present obvious problems. In preliminary studies we found that the loading dose and maintenance infusion sequence outlined in Methods (derived from a pharmacokinetic model of intravenous thiopentone distribution ${ }^{16}$ ) provided fairly constant ventilation and end-tidal $\mathrm{PCO}_{2}$ over 30 to 45 minutes in most subjects. To avoid long periods of testing in which large doses of thiopentone would accumulate, brief tests of the activity of ventilatory reflexes were required. Our methods created hypoxic and hypercarbic stimuli progressively, yielding a relatively large number of data points in a short period of time.

The values of ventilation and responses to carbon dioxide which we observed were in accord with the results of previous investigations. In agreement with observations of normal subjects sedated with pentobarbitone and secobarbitone, ${ }^{17.18}$ thiopentone sedation did not significantly alter resting ventilation, resting endtidal carbon dioxide tension or the ventilatory response to carbon dioxide (Table I, Figure 2). Thiopentone anaesthesia reduced minute ventilation, increased end-tidal $\mathrm{PCO}_{2}$ (Table I) and shifted the ventilation: $\mathrm{PCO}_{2}$ response to the right as well as reducing its slope (Figure 1). In addition, anaesthesia altered the pattern of unstimulated ventilation to one of smaller tidal volumes and increased respiratory frequencies. All of these effects of thiopentone are well-known. ${ }^{19,20}$ (Note that in this study, conscious subjects were studied seated, while sedated and anaesthetized subjects were supine. This position difference has no effect on control of ventilation in the conscious state, 21 and therefore should not have influenced our comparisons).

The important new information we are reporting is the influence of thiopentone on isocapnic hypoxic ventilatory response. Thiopentone sedation did not appear to alter this response (Table I, Figure 2). Hirshman, et al. studied ventilatory responses to hypoxia in awake and pentobarbitone ( $2 \mathrm{mg} / \mathrm{kg}$ I.M.) sedated human subjects. They observed no mean change in the ventilatory 

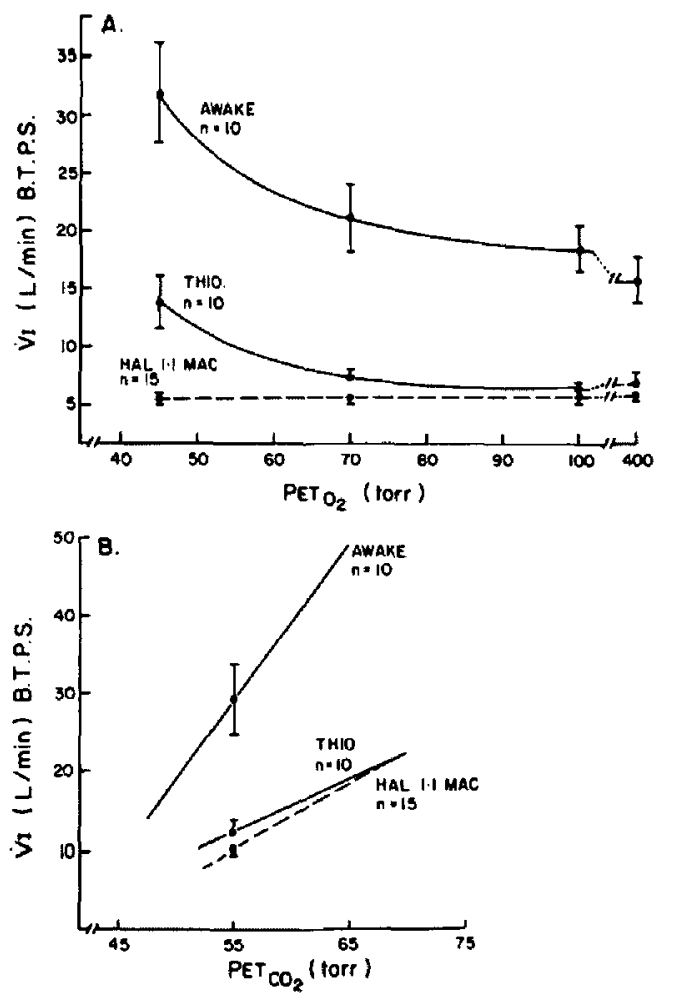

Figure 1. A. Mean ventilatory response to isocapnic hypoxia of subjects anaesthetized with thiopentone (THIO), and awake controls (AWAKE). The broken line represents the mean response of previously studied subjects anaesthetized with halothane 1.1 MAC. ${ }^{6}$ The mean PET $\mathrm{CO}_{2}$ values (士S.E.M.) of awake, thiopentone and halothane states were $44 \pm 1+43 \pm 2$ and $43 \pm 1$ torr $(5.85 \pm 0.13,5.72 \pm 0.27$ and $5.72 \pm 0.13$ $k P a)$ respectively. Each response is repre sented by four points, the mean inspired ventilations $( \pm S$.E.M.) at PET $_{0_{2}}$ values of $400,100,70$ and 45 torr $(53.1,13.3,9.31$ and $5.99 \mathrm{kPa}$ ). Lines approximating the usual responses are hand-drawn through the points. Thiopentone anaesthesia reduced the ventilatory response to hypoxia; however, the response was not totally abolished, as with halothane.

B. Mean ventilatory response to hypercarbia of subjects anaesthetized with thiopentone (THIO), controls (AWAKE) and subjects anaesthetized with halothane 1.1 MAC. Dots depict the mean ventilation (IS.E.M.) at a $P E T_{\mathrm{CO}_{2}}$ of 55 torr $(7.32 \mathrm{kPa})$ and lines represent mean responses over the $\mathrm{PET}_{\mathrm{CO}}$ range tested. Thiopentone ande sthesia reduced the ventilatory response to carbon dioxide by a magnitude similar to that previously observed with halothane 1.1 MAC.

response to hypoxia during sedation, although they point out that in a few individual subjects there was a slight depression. ${ }^{17}$ We would attribute these individual findings to failure to maintain strict isocapnic conditions and/or the normal variability of data associated with their method. ${ }^{22}$ In

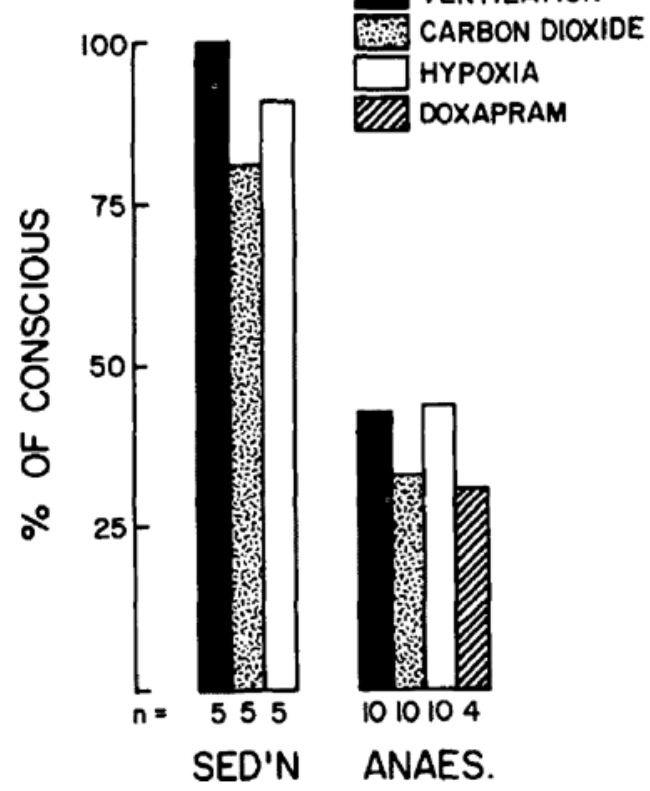

Figure 2. Ventilation and ventilatory responses during thiopentone sedation and anaesthesia. Bars represent mean values of ventilation and parameters of response to carbon dioxide, hypoxia and doxapram (see text), all as a percentage of awake values. Thiopentone sedation did not significantly alter ventilation or any response tested. Thiopentone antesthesia reduced isocapnic ventilation and the ventilatory responses to hypercarbia, hypoxia and doxapram. During anaesthesia, all mean values decreased approximately in parallel.

our study, thiopentone anaesthesia produced a clear reduction in the isocapnic ventilatory response to hypoxia (Table I, Figure 1) by a magnitude which closely paralleled anaesthesia induced reductions in isocapnic resting ventilation and the ventilatory response to carbon dioxide (Figure 2). This proportionate depression applied to both the mean group results and individual values; there was a significant correlation between reductions of hypoxic response $\left(\Delta \dot{V}_{I_{45}}\right)$ and resting ventilation of individual anaesthetized subjects $(r=0.63, P<0.05)$.

Like the response to hypoxia, the ventilatory response to a small dose of doxapram $0.4 \mathrm{mg} / \mathrm{kg}$ is mediated by peripheral chemoreceptors in man. ${ }^{23}$ Thiopentone anaesthesia reduced this low-dose doxapram response in parallel with the hypoxic response, and thus in parallel with ventilation and the carbon dioxide response (Figure 2).

In classical animal experiments, it was repeatedly shown that while barbiturate anaesthesia depressed minute ventilation and the car- 
bon dioxide response, it preserved a near normal ventilatory reaction to hypoxia, even when anaesthesia was quite deep. ${ }^{24-26}$ The difference in the present human data could well be speciesrelated. However, there is another factor which may be important. At the time of the interpretation of the older data, the influence of carbon dioxide levels on hypoxic responses was not generally recognized and the activity of hypoxic reflexes of normocapnic conscious dogs was compared with the activity of responses of hypercapnic anaesthetized dogs. Today, it is established that hypercarbia potentiates the hypoxic chemoreflex; hence the requirement for strict isocapnic conditions in comparative studies. If we were to compare our slightly hypercarbic anaesthetic responses with those of a normocapnic awake group (e.g. the controls of the sedation group in Table 1), we, like the earlier investigators, might erroneously conclude that thiopentone anaesthesia does not influence the ventilatory response to hypoxia. The older studies made the qualitative observation that in deep thiopentone anaesthesia, when the carbon dioxide response was totally absent, ventilation continued solely on the basis of a still-active hypoxic response. ${ }^{24}$ The present data do not exclude the possibility that deep thiopentone anaesthesia in man might preserve a vestigial hypoxic response when the carbon dioxide chemoreflex is totally abolished.

During thiopentone anaesthesia in this study, the mean changes in resting ventilation, pattern of ventilation and response to carbon dioxide were fortuitously almost identical to changes we previously observed during halothane anaesthesia at 1.1 MAC. ${ }^{6}$ Although thiopentone and halothane anaesthesia were similar in these ventilatory effects, each had a very different impact on the ventilatory response to hypoxia. (Some of the mean halothane 1.1 MAC data of the previous study are included for comparison in Figure 1.) Thiopentone anaesthesia reduced the hypoxic reflex, but it did so only in proportion to a reduced ventilation and ventilatory response to carbon dioxide. In contrast, halothane selectively abolished the hypoxic response (Figure 1). Similarly, thiopentone reduced the doxapram $(0.4$ $\mathrm{mg} / \mathrm{kg}$ ) response in proportion to overall ventilatory depression while halothane selectively eliminated this response too. ${ }^{6}$ The comparison suggests a qualitatively different action of these two drugs on components of ventilatory control involved in mediating responses to hypoxia and low-dose doxapram, that is the peripheral chemoreceptors, their immediate central neural connections and neural circuits which modulate chemoreceptor transfer functions and medullary processing of chemoreceptor input. ${ }^{5}$

In absolute values, the response to hypoxia during light thiopentone anaesthesia remained brisk and quantitatively the same as that of normocapnic awake controls (Table I). As previously noted, this "normal" absolute response depended upon the concurrent hypercarbia present during anaesthesia. From the clinical point of view, it is reasonable to conclude that light thiopentone anaesthesia, unlike halothane anaesthesia, does not critically impair this important ventilatory refiex.

\section{SUMMARY}

We have assessed the impact of thiopentone on the hypoxic ventilatory reflex, and on the responses to carbon dioxide and doxapram. Thiopentone sedation did not detectably alter any of these aspects of ventilatory control. Thiopentone anaesthesia reduced ventilation and the ventilatory responses to hypoxia, carbon dioxide and doxapram, all approximately in parallel. We conclude that, in contrast to halothane, thiopentone does not selectively reduce the ventilatory response to hypoxia. During light thiopentone anaesthesia, a reasonably brisk hypoxic response is present.

\section{RÉSUMÉ}

Nous avons évalué l'influence du thiopenthal sur la réponse ventilatoire réflexe secondaire à I'hypoxie, à des variations de $\mathrm{PCO}_{2}$ et enfin au doxapram. Les doses sédatives de thiopenthal ne modifiaient pas significativement ces réflexes, alors que des doses anesthésiques de cet agent diminuaient de façon parallèle la ventilation ainsi que la ventilation réflexe secondaire à l'hypoxie, aux modifications de la $\mathrm{CO}_{2}$ et au doxapram. Nous concluons que le thiopenthal ne réduit pas de façon sélective la réponse ventilatoire réflexe à I'hypoxie; l'halothane exerce, par contraste, une telle activité sélective. Sous anesthésie légère au thiopenthal, la réponse à l'hypoxie est assez vive.

\section{ACKNOWLEDGEMENTS}

Thanks are due to Miss Jane Clement for assistance in conducting studies and analysis of data, to Dr. W.E. Spoerel for assistance with the sedation studies, to Dr. R.I. Brooke and Dr. I.D.F. 
Schofield for agreeing to participation of their patients in this study, to Dr. A.C. Bryan of the University of Toronto for constant interest and encouragement, to Miss C. O'Connor and Mrs. L. Nolan for manuscript typing and to the subjects who gave freely of time and ventilatory control in order to participate in this study.

\section{ABBREVIATIONS}

\begin{tabular}{|c|c|}
\hline $\mathrm{PET}_{\mathrm{CO}}$ & $=$ end-tidal carbon dioxide tension \\
\hline $\mathrm{PET}_{\mathrm{O}_{2}}$ & $=$ end-tidal oxygen tension \\
\hline & $=$ inspired minute ventilation \\
\hline$\Delta \dot{V}_{I_{45}}$ & $\begin{aligned}= & \text { isocapnic increment of inspired } \\
& \text { minute ventilation from hyperoxia } \\
& \text { to a } \text { PET }_{\mathrm{O}_{2}} \text { of } 45 \text { torr }\end{aligned}$ \\
\hline "A" & $\begin{aligned}= & \text { calculated variable of hypoxic } \\
& \text { responsiveness (see Methods) }\end{aligned}$ \\
\hline $\mathrm{FI}_{\mathrm{O}_{2}}$ & $=$ inspired oxygen concentration \\
\hline S.D. & $=$ standard deviation \\
\hline S.E.M. & $=$ standard error of the mean \\
\hline B.T.P.S & $\begin{array}{c}=\text { body temperature and ambient } \\
\text { pressure, saturated }\end{array}$ \\
\hline
\end{tabular}

\section{REFERENCES}

1. Comroe, J.H. The peripheral chemoreceptors, Handbook of Physiology, Respiration. Vol. 1. Edited by Fenn, W.O. \& Rahn, H. Washington: American Physiological Society (1964).

2. Kontos, H.A.. Levasseur, J.E., Richardson, D.W., Mauck, H.D., \& Patterson, J.L. Comparative circulatory responses to systemic hypoxia in man and in unanaesthetized dogs. J. Appl. Physiol. 23: 381 (1967)

3. SeVeringhaus, J.W. Hypoxic respiratory drive and its loss during chronic hypoxia. Clin. Physiol. 2(1): 57 (1972).

4. BLACK, A.H.S., COMroE, J.H., \& JaCOBS, L. Species difference in carotid body response of cat and $\operatorname{dog}$ to dopamine and serotonin. Am. J. Physiol. 223(5): 1097 (1972).

5. TENNeY, S.M., SCOtro, P., Ou, L.C., Bartlett, D., \& REMmERS, J.E. Supra-pontine influences on hypoxic ventilatory control, CIBA Foundation Symposium on High Altitude Physiology. Edited by Knight, J. \& Porter, R. London: ChurchillLivingston (1971).

6. KNILL, R.L.\& GELB, A.W. Ventilatory response to hypoxia and hypercapnia during halothane sedation and anaesthesia in man. Anesthesiology, in press.

7. Yacoub, O, Doell, D., Kryger, M.H., \& ANTHONISEN, N.R. Depression of hypoxic ventilatory response by nitrous oxide. Anesthesiology 45(4): 385 (1976).

8. Weil, J.V., BYrne-QuinN, E., \& SOdal, W. Hypoxic ventilatory drive in normal man. J. Clin. Invest. 49: 1061 (1970).
9. READ, D.J.C. A clinical method for assessing the ventilatory response to $\mathrm{CO}_{2}$. Australasian Ann. Med. 16: 20 (1967).

10. READ, D.J.C. \& LEIGH, J. Blood-brain tissue $\mathrm{PCO}_{2}$ relationships and ventilation during rebreathing. $J$. Appl. Physiol. 23(1): 53(1967)

11. WAdE, J.G.. LARSON, C.P., \& Hickey, R.F. Effect of carotid endarterectomy on carotid chemoreceptor and baroreceptor functions in man. N. Eng, J Med. 282(15): 823 (1970).

12. Flenley, D.C. \& Millar, J.S. Ventilatory response to oxygen and carbon dioxide in chronic respiratory failure. Clin. Science 33: 319 (1967).

13. Anthonisen, H.R., Bradley, C. A., \& Dhingra, $S$. Control of ventilation in chronic respiratory failure. Clin. Research 25(5):711A (1977).

14. Zwillich, C.W., Sutton, F.D., Pierson, D.J., Creagh, E.M., \& WeIL, J.V. Decreased hypoxic ventilatory drive in the obesity-hypoventilation syndrome. Am. J. Medicine 59(3): 343 (1975).

15. WeIL, J.V., MCCUllough, R.E., \& Kline, J.S. Diminished ventilatory response to hypoxia and hypercapnia after morphine in normal man. New England J. Med. 292: 1103 (1975).

16. Price, H.L., Kounat, P.J., Safer, J.N. ConNOR, E.H., \& PRICE, M.L. The uptake of thiopental by body tissues and its relation to the duriation of narcosis. Clin. Pharmacol. Therap. 1: 16 (1960).

17. Hirshman, C.A., McCullough, R.E., Cohen, P.J., \& WEIL, J.V. Effect of pentobarbitone on hypoxic ventilatory drive in man. Br. J. Anaesthesia 47: 963 (1975).

18. Stephen, G.W., Banner, M.P., Wollman, H. \& SMITH, T.C. Respiratory pharmacology of mixtures of scopolamine with secobarbital and with fentanyl. Anesthesiology 31:237 (1970).

19. Wyant, G.M., Dobkin, A.B., \& AasheiM, G.M. Comparisons of seven intravenous anaesthetic agents in man. Brit. J. of Anesthe sia 29: 194 (1957).

20. ECKenhoff, J.E. \& Helrich, M. The effect of narcotics, thiopental and nitrous oxide upon respiration and respiratory response to hypercapnia. Anesthesiology 19:240 (1958).

21. Rigg, J.R.A., Rebuck, A.S., \& CAMpbell, E.J.M. The effect of posture on the ventilatory response to $\mathrm{CO}_{2}$. J. Appl. Physiol. 37: 487 (1974).

22. SAHN, S.A., ZWILLICH, C.W., DiCk, N., MCCULLOUGH, R.E., \& WEIL, J.V. Variability of ventilatory response to hypoxia and hypercapnia. J. Appl. Physiol, 43(6): 1019 (1977)

23. Severinghaus, J., Ozanne, G., \& Massuda, Y. Measurement of the ventilatory response to hypoxia. Chest $70(1): 121$ (1976).

24. MOYER, C.A. \& BEECHER, H.K. Effects of barbiturate anaesthesia upon the integration of respiratory control mechanisms. J. Clin. Invest. 21:429 (1942).

25. DRIPPS, R.D. \& DUmke, P.R. The effect of narcotics on the balance between central and chemoreceptor control of respiration. J. Pharm. Exp. Ther. $77: 290$ (1943).

26. Marshall, E.K.\& Rosenfeld. M. Depression of respiration by oxygen. J. Pharmacol. Exp. Ther. 57: 437 (1936). 